\title{
A putative Chondroprotective role for IL-1 $\beta$ and MPO in herbal treatment of experimental osteoarthritis
}

\author{
Nora M. Aborehab ${ }^{1}$, Mahitab H. El Bishbishy ${ }^{2}$, Abeer Refaiy ${ }^{3}$ and Nermien E. Waly ${ }^{4^{*}}$ (D)
}

\begin{abstract}
Background: Herbal treatment may have a chondroprotective and therapeutic effect on Osteoarthritis (OA). We investigated the mechanism of action of ginger and curcumin rhizomes cultivated in Egypt in treatment of OA in rat model.

Methods: Thirty-five albino rats were intra-articularly injected with Monosodium lodoacetate in the knee joint. Ginger and curcumin was orally administered at doses of 200 and $400 \mathrm{mg} / \mathrm{kg}$ (F200 and F400). Serum levels of cartilage oligomeric matrix protein (COMP), hyaluronic acid (HA), malondialdehyde (MDA), myeloperoxidase (MPO), Interleukin-1 beta (IL-1 $\beta$ ) and superoxide dismutase activity (SOD) were measured using ELISA. The composition of the herbal formula hydro-ethanolic extract was characterized using UPLC-ESI-MS. Histopathological changes in injected joints was examined using routine histopathology. Statistical analysis was performed using oneway ANOVA.

Results: Serum levels of COMP, HA, MPO, MDA, and IL-1 $\beta$ were significantly decreased in F 200, F 400 and $V$ groups when compared to OA group ( $P$ value $<0.0001$ ). On the other hand SOD levels were significantly elevated in treated groups compared to OA groups (P value $<0.0001$ ).

Conclusions: The ginger/curcumin at 1:1 had chondroprotective effect via anti-inflammatory and antioxidant effect in rat OA model. Further pharmacological and clinical studies are needed to evaluate this effect.
\end{abstract}

Keywords: Ginger, Curcumin, Osteoarthritis, IL-1ß, COMP, HA, MPO, MDA

\section{Background}

Osteoarthritis $(\mathrm{OA})$ is a common degenerative joint disease in the elderly and a leading cause of physical disability worldwide [1]. It mainly affects the weight- bearing joints, such as hips and knees [2]. OA is a degenerative disease characterized by structural changes of the knee joint including articular cartilage erosion, synovitis and remodeling of subchondral bone [3]. Patients affected by OA experience pain that worsens with motion, exercise and, with pathology progression, also at rest [4]. It was proposed that OA is the result of both mechanical and biological changes, causing loss of the normal homeostatic

\footnotetext{
* Correspondence: nwaly@icloud.com

${ }^{4}$ Department of Physiology, Faculty of Medicine, Helwan University, Cairo,

11795, Egypt

Full list of author information is available at the end of the article
}

mechanism occurring between catabolic and anabolic processes in the articular cartilage. Chondrocyte in the mature articular cartilage is the only type of cell that is capable of production and maintenance of the extracellular matrix. Therefore any reduction in chondrocyte density will contribute to the development of OA [5]. To date, there is no effective pharmacological treatment for $\mathrm{OA}$ and the end stage of disease usually requires joint replacement surgery $[6,7]$.

A monosodium Iodoacetate (MIA) induced OA model is well described in rats especially in terms of the pathological progression of the disease. It triggers changes similar to the histological and pathophysiological features of that in human OA. The mechanism of action of MIA has been attributed to inhibition of glyceraldehyde-3-phosphate dehydrogenase. This disrupts the glucose metabolism of chondrocytes, leading to reactive oxygen species (ROS) production and caspase 
activation, and further to the catabolism of cartilage matrix and cell death, that can be detected both in vivo and in vitro. It therefore targets the avascular cartilage and causes chondrocyte death, fragmentation of cartilage and exposure of subchondral tissue. In addition to evoking cartilage degradation, MIA induces an acute inflammation, which is associated with increased expression of pro-inflammatory factors such as IL- $1 \beta$ IL-6, IL-15, COX-2 and metalloproteinase [8-10].

Since the pharmacologic treatment has several limitations and is not always effective in the management of $\mathrm{OA}$, researchers have been striving to find alternative therapeutic agents. Herbs and extracts present a potential hope for treatment of many diseases. The use of tomato and broccoli extracts has been shown to have beneficial effect in the treatment of obesity both in rats and humans [11-13].

Ginger, Zingiber officinale Rosc., rhizomes have been shown to contain a large amount of zerurnbone [14]. Zerurnbone has been shown to have anticancer and antioxidant actions [5]. In addition several studies has shown that ginger possesses medicinal effects in animals. Its ethanol extract had hypoglycemic and anti-inflammatory effects in rats [15]. Another study has shown that ginger protects against ulcer development in albino rats [16]. Ginger also has been shown to exert chondroprotective effects in an experimental model of OA in rats [5]. In addition it is safe to use as the $\mathrm{LD}_{50}$ of ginger extract was is up to $1 \mathrm{~g} / \mathrm{kg}$ [17].

Curcuma longa L., Zingiberaceae (turmeric) is a herb that is used in the Fareast folk medicine for the treatment of biliary disorders among other diseases [18]. Its extract has been shown to have beneficial effects in the treatment of $\mathrm{OA}$ through lowering oxidative stress and reducing inflammation $[19,20]$. It has also been shown to have protective effects against rheumatoid arthritis in rat model [21]. Furthermore, ginger has no toxic effects when administered up to $5 \mathrm{~g} / \mathrm{kg}$ in rats which provides wide safety margin of testing for its beneficial effects [22].

The aim of this study was to characterize the composition of the ginger and turmeric herbal formula hydro-ethanolic extract evaluate the possible chondroprotective effect of a mixed formula of both herbs in MIA induced $\mathrm{OA}$ rat model. In addition we investigated the possible mechanism of action of the herbal formula and examine its histopatholgical effect compared it to standard therapeutic agents.

\section{Methods}

\section{Animals}

Thirty-five male albino rats, weighing $200 \pm 30 \mathrm{~g}$ at the start of the experiments were used. Prior to the initiation of the studies, the animals were randomized and assigned to treatment groups. Four rats were housed per cage $($ size $26 \times 41 \mathrm{~cm}$ ) and placed in the experimental room for acclimatization $24 \mathrm{~h}$ before any procedure was carried out. The animals were fed with standard laboratory diet and tap water ad libitum, and kept in an airconditioned animal room at $23 \pm 1{ }^{\circ} \mathrm{C}$ with a $12 \mathrm{~h}$ light/ dark cycle.

Animal care and handling was performed in conformance with approved protocols of Cairo University and Egyptian Community guidelines for animal care. Research Ethics Committee at MSA School of Pharmacy approved the protocol of this study.

\section{Monosodium iodoacetate injection}

A single intra-articular (i.a.) injection of $2 \mathrm{mg}$ of MIA (Sigma-Aldrich, Egypt) was performed through the infra-patellar ligament into the joint space of the right knee of lightly anesthetized rats (3\% isoflurane in $\mathrm{O} 2$ at $1.5 \mathrm{l} / \mathrm{min}$ ) in a total volume of $50 \mu \mathrm{l}$ saline according to methodology of Nagase et al., 2012 [8].

\section{Plant material}

Fresh rhizomes of $Z$. officinale Rosc., and C. longa L., Zingiberaceae were purchased from the local market, Giza, Egypt during 2015/2016. The taxonomical identity was kindly verified by Dr. Mohamed El Gebaly, National Research Center, Giza, Egypt. The plant samples were air dried in the absence of direct sunlight and ground just before extraction.

\section{Herbal formula preparation}

The plant material was separately grinded then mixed together in a $1: 1$ ratio, macerated in $70 \%$ ethanol till exhaustion. The hydro-ethanolic extracts were concentrated under reduced pressure and kept in tightly closed amber glass containers for LC-ESIMS and biological analysis. A voucher specimen (RS 0019) was deposited in the herbarium of faculty of Pharmacy, MSA University.

\section{Experimental groups}

Rats were randomly allocated into five groups of seven animals each.

Group 1: Normal control group injected (i.a) by $50 \mu \mathrm{l}$ saline in the right knee.

Group 2 (OA): rats injected (i.a) of 2 mg of MIA in a total volume of $50 \mu \mathrm{l}$ saline in the right knee.

Group 3 (F 200): Osteoarthritic rats treated with Herbal formula $200 \mathrm{mg} / \mathrm{kg} /$ day, orally for 1 month.

Group 4 (F 400): Osteoarthritic rats treated with Herbal formula $400 \mathrm{mg} / \mathrm{kg} /$ day, orally. For 1 month.

Group $5(\mathrm{~V})$ : Osteoarthritic rats treated with Voltaren $30 \mathrm{mg} / \mathrm{kg} /$ day, orally for 1 month.

Doses were selected based on previous published results of toxicity studies in similar species $[17,22]$. 


\section{Drugs}

Voltaren (Novartis, Egypt) were dissolved in distilled water and administered orally.

\section{Chemicals}

Ethanol was of HPLC grade and purchased from SigmaAldrich (Steinheim, Germany).

\section{Blood samples and biochemical analysis}

At the end of the study, rats were fasted overnight, anesthetized with thiopental sodium $(50 \mathrm{mg} / \mathrm{kg}$ ) [23] and blood samples were collected in the morning $(5 \mathrm{ml}$ per rat). Blood samples were centrifuged at $3000 \mathrm{rpm}$ for 15 min after 30 min of collection and stored at $-80{ }^{\circ} \mathrm{C}$ until analyzed. Serum cartilage oligomeric matrix protein (COMP), Hyaluronic acid (HA), Interleukin-1 $\beta$ (IL-1), Myeloperoxidase (MPO), Superoxide dismutase (SOD) were measured using the corresponding rat enzyme immunoassay kits (COMP: Cusabio Biotech Co, China), (HA: Uscn Life Science Inc. Wuhan, China), (IL-1: Koma Biotech Inc., Korea), (MPO: Hycult Biotech, Netherland), and (SOD: Cusabio Biotech Co, China) according to manufactured instructions. Serum Malondialdehyde (MDA): Cell Biolabs, Inc., USA was determined quantitatively using spectrophotometric method.

\section{Histopathological examination}

Anesthetized rats (thiopental sodium (50 $\mathrm{mg} / \mathrm{kg})$ [23])were rapidly decapitated; knee joints were dissected, rinsed in saline. Specimens were fixed in $10 \%$ formalin and then joints were decalcified in nitric oxide for 4 days, routinely processed and embedded in paraffin. Five microns sections were cut and stained with hematoxylin and Eosin (H\&E). Histopathological evaluation were done according to Osteoarthritis Research Society International (OARSI) cartilage OA grading system [24].

\section{UPLC-ESI-MS apparatus}

The analysis was performed on a MS QQQ mass spectrometer coupled to Aglient 6420 series UPLC system (Agilent Technologies, Waldbronn, Germany), equipped with a 1290 ultra-performance auto sampler, 1290 infinity Quad pump, and 6420 triple quadrupole detector. Chromatographic separation was performed on a Acquity UPLC ${ }^{\circledast}$ HSS T3 $(150 \mathrm{~mm} \times 2.1 \mathrm{~mm}$ i.d.; $1.8 \mu \mathrm{m})$ column (Waters, USA).

\section{Identification of the major compounds}

Mobile phase consisted of two solvents, (A) 10\% acetonitrile and (B) water. The separation was performed using gradient elution, from $15 \%$ to $90 \% \mathrm{~A}$ at $40{ }^{\circ} \mathrm{C}$ at a flow rate of $0.35 \mathrm{~mL} / \mathrm{min}$. Sample injection volume was $5 \mu \mathrm{L}$. The ionization technique was electrospray ionization. Spectra were recorded in negative ion mode between $\mathrm{m} / \mathrm{z} 50$ and 1000 with capillary voltage, $4500 \mathrm{~V}$ and heated dry nitrogen gas temperature, $325{ }^{\circ} \mathrm{C}$ and flow rate $9 \mathrm{l} / \mathrm{min}$, the gas flow to the nebulizer was set at pressure $60 \mathrm{psi}$.

\section{Statistical analyses}

All data were expressed as mean \pm SEM and analyzed using Prism program version 6. For all parameters, comparisons among groups $(N=7)$ were carried out using one-way analysis of variance (ANOVA) followed by Bonferroni's multiple comparisons test. All $P$ values reported are twotailed and $P<0.05$ was set as the level of significance.

\section{Results}

Effect of herbal formula treatment on blood cartilage oligomeric matrix protein (COMP)

Mean serum level of COMP was significantly increased in OA group compared to the control group ( $P$ value $<0.0001)$. On the other hand, the mean serum level of COMP was significantly decreased in F 200, F 400 and $\mathrm{V}$ groups when compared to $\mathrm{OA}$ group ( $\mathrm{P}$ value $<0.0001)$. The mean serum level of COMP was significantly decreased in F 400 group compared to F 200 group $(P$ value $<0.0001)$. Non-significant difference of COMP serum level was found between F 400 group and $\mathrm{V}$ group (Figure 1a).

Effect of herbal formula on blood hyaluronic acid (HA) Mean serum level of HA was significantly increased in OA group compared to the control group ( $P$ value $<0.0001)$. The mean serum level of HA was significantly decreased in F 200, F 400 and V groups when compared to OA group $(P$ value $<0.0001)$. The mean serum level of HA was significantly decreased in F 400 group compared to F 200 group ( $P$ value $<0.0001)$. Also a significant difference was found between $\mathrm{V}$ and $\mathrm{F} 400$ groups $(P$ value $<0.005)$ (Fig. 1b).

Effect of herbal formula on blood myeloperoxidase (MPO) Mean serum level of MPO was significantly increased in OA group compared to the control group ( $P$ value $<0.0001)$. The mean serum level of MPO was significantly decreased in F 200, F 400 and V groups when compared to OA group ( $P$ value $<0.0001)$. The mean serum level of MPO was significantly decreased in F 400 group compared to $\mathrm{F} 200$ group ( $P$ value $<0.0001)$. A significant difference was found between $\mathrm{V}$ and $\mathrm{F} 400$ groups (P value <0.01) (Fig. 2).

Effect of herbal formula on blood Interleukin-1 beta (IL-1 $\beta$ ) Mean serum level of IL-1 $\beta$ was significantly increased in OA group compared to the control group $(P$ value $<0.0001)$. The mean serum level of IL-1 $\beta$ was significantly decreased in F 200, F 400 and V groups when compared 
a

The effect of herbal formula treatment on serum COMP

\section{b}

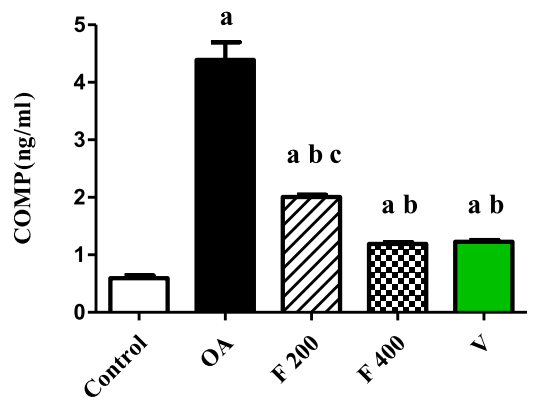

The effect of herbal formula treatment on serum hyaluronic acid

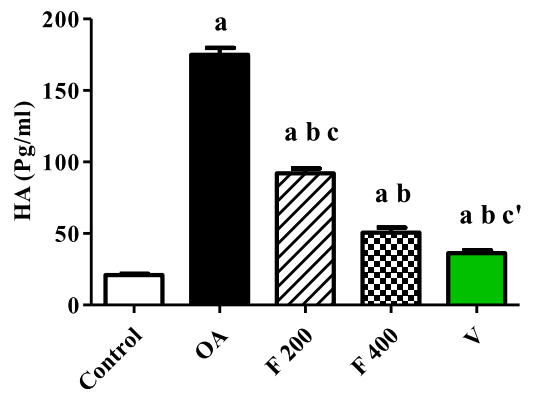

Fig. 1 a Serum level of COMP $(\mathrm{ng} / \mathrm{ml})$ in the experimental groups. Herbal formula treatment decreased serum level of COMP in the osteoarthritic rats at the end of 1 month treatment; $\mathrm{C}=$ control; $\mathrm{OA}=$ osteoarthritis; $\mathrm{F} 200=$ herbal formula $200 \mathrm{mg} / \mathrm{kg} ; \mathrm{F} 400$ = herbal formula $400 \mathrm{mg} / \mathrm{kg} ; V=$ Voltaren. Results were expressed as mean $\pm \mathrm{SEM}$ and analyzed using one-way ANOVA followed by Bonferroni's post hoc test $\mathrm{a}=$ Significant from control at $P<0.0001, \mathrm{~b}=$ Significant from $\mathrm{OA}$ at $P<0.0001, \mathrm{c}=$ Significant from $\mathrm{F} 400$ at $P<0.0001$. b Serum level of $\mathrm{HA}(\mathrm{Pg} / \mathrm{ml})$ in the experimental groups. Herbal formula treatment decreased serum level of $\mathrm{HA}$ in the osteoarthritic rats at the end of 1 month treatment; $\mathrm{C}=$ control; $\mathrm{OA}=$ osteoarthritis; $\mathrm{F} 200=$ herbal formula $200 \mathrm{mg} / \mathrm{kg} ; \mathrm{F} 400$ = herbal formula $400 \mathrm{mg} / \mathrm{kg} ; \mathrm{V}=$ Voltaren. Results were expressed as mean \pm SEM and analyzed using one-way ANOVA followed by Bonferroni's post hoc test $\mathrm{a}=$ Significant from control at $P<0.0001, \mathrm{~b}=$ Significant from OA at $P<0.0001$, $\mathrm{c}=$ Significant from $\mathrm{F} 400$ at $P<0.0001, \mathrm{C}^{\prime}=$ Significant from $\mathrm{F} 400$ at $P<0.005$

to OA group ( $P$ value $<0.0001)$. The mean serum level of IL-1 $\beta$ was significantly decreased in F 400 group compared to F 200 group ( $P$ value $<0.0001)$. A significant difference was found between $\mathrm{V}$ and $\mathrm{F} 400$ groups ( $P$ value $<0.002$ ) (Fig. 3).

\section{Effect of herbal formula on blood malondialdehyde (MDA) and superoxide dismutase (SOD)}

Mean serum level of MDA was significantly increased in OA group compared to the control group ( $P$ value $<0.0001)$. The mean serum level of MDA was significantly decreased in F 200, F 400 and V groups when compared to OA group $(P$ value $<0.0001)$. The mean serum level of MDA was significantly decreased in $\mathrm{F}$
The effect of herbal formula treatment on serum MPO

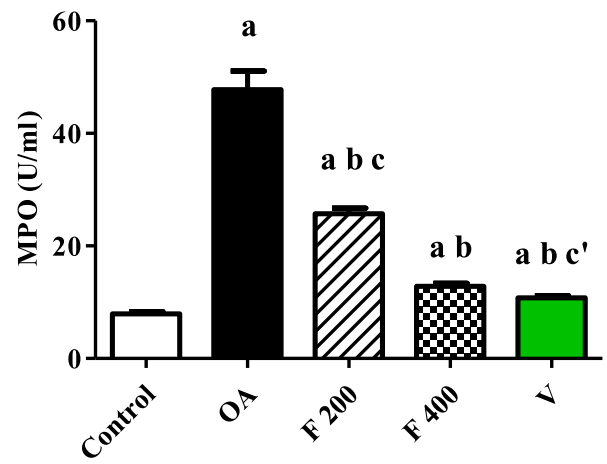

Fig. 2 Serum level of MPO $(\mathrm{U} / \mathrm{ml})$ in the experimental groups. Herbal formula treatment decreased serum level of MPO in the osteoarthritic rats at the end of 1 month treatment; $\mathrm{C}=$ control; $\mathrm{OA}=$ osteoarthritis; F 200 = herbal formula 200 mg/kg; F 400 = herbal formula 400 mg/kg; $V=$ Voltaren. Results were expressed as mean \pm SEM and analyzed using one-way ANOVA followed by Bonferroni's post hoc test $\mathrm{a}=$ Significant from control at $P<0.0001, \mathrm{~b}=$ Significant from $\mathrm{OA}$ at $P<0.0001, C=$ Significant from $F 400$ at $P<0.0001, C^{\prime}=$ Significant from F 400 at $P<0.01$

400 group compared to $\mathrm{F} 200$ group $(P$ value $<0.0001)$. While non-significant difference was found between F 400 and V groups. (Fig. 4).

The mean serum level of SOD was significantly decreased in $\mathrm{OA}$ group compared to the control group, while it was increased in F 200, F 400 and V groups when compared to OA group $(P$ value $<0.0001)$. The mean serum level of SOD was significantly increased in F 400 group compared to F 200 group ( $P$ value $<0.0001$ ) and non-significant difference was found between F 400 and V groups. (Fig. 5).

The effect of herbal formula treatment on serum IL-1 Beta

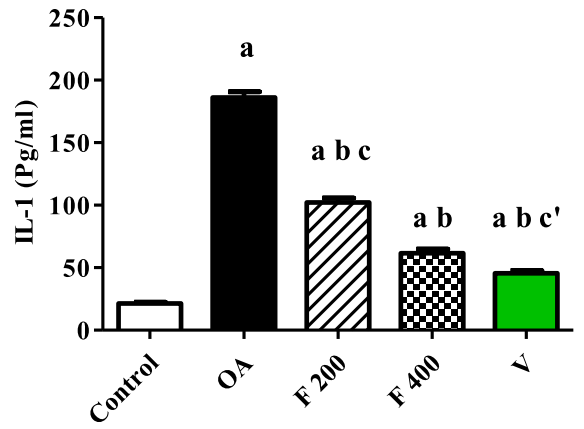

Fig. 3 Serum level of IL-1 Beta $(\mathrm{Pg} / \mathrm{ml})$ in the experimental groups. Herbal formula treatment decreased serum level of IL-1 Beta in the osteoarthritic rats at the end of 1 month treatment; $C=$ control; $\mathrm{OA}=$ osteoarthritis; F 200 = herbal formula $200 \mathrm{mg} / \mathrm{kg}$; F $400=$ herbal formula $400 \mathrm{mg} / \mathrm{kg} ; \mathrm{V}=$ Voltaren. Results were expressed as mean \pm SEM and analyzed using one-way ANOVA followed by Bonferroni's post hoc test, $a=$ Significant from control at $P<0.0001$, $\mathrm{b}=$ Significant from $\mathrm{OA}$ at $P<0.0001, \mathrm{c}=$ Significant from $\mathrm{F} 400$ at $P<0.0001, C^{\prime}=$ Significant from $F 400$ at $P<0.002$ 
The effect of herbal formula treatment on serum MDA

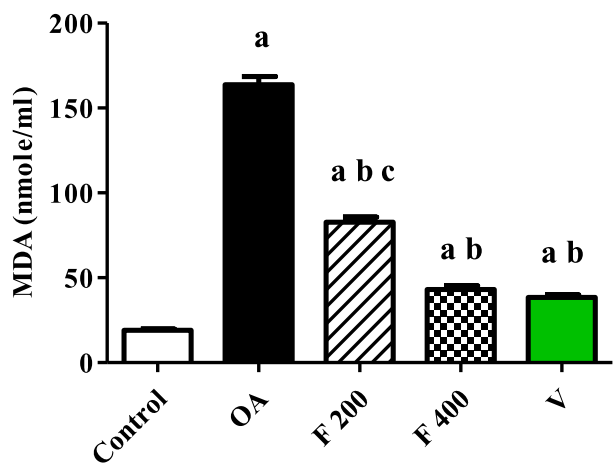

Fig. 4 Serum level of MDA (nmole/ml) in the experimental groups. Herbal formula treatment decreased serum level of MDA in the osteoarthritic rats at the end of 1 month treatment; $\mathrm{C}=$ control; $\mathrm{OA}=$ osteoarthritis; $\mathrm{F} 200=$ herbal formula $200 \mathrm{mg} / \mathrm{kg} ; \mathrm{F} 400=$ herbal formula $400 \mathrm{mg} / \mathrm{kg} ; \mathrm{V}=$ Voltaren. Results were expressed as mean \pm SEM and analyzed using one-way ANOVA followed by Bonferroni's post hoc test, $a=$ Significant from control at $P<0.0001, b=$ Significant from $\mathrm{OA}$ at $P<0.0001, \mathrm{C}=$ Significant from $\mathrm{F} 400$ at $P<0.0001$

\section{UPLC-ESI-MS characterization of the herbal formula} UPLC-ESI-MS analysis of the hydro-ethanolic extract of the herbal formula demonstrated the presence of several gingerol derivatives in addition to curcumin and dihydro-curcumin as previously reported in different ginger and turmeric extracts [25-29]. In total, 11 compounds belonging to different classes were tentatively identified by UPLC-MS. Data of peaks identification, retention times,

The effect of herbal formula treatment on serum SOD

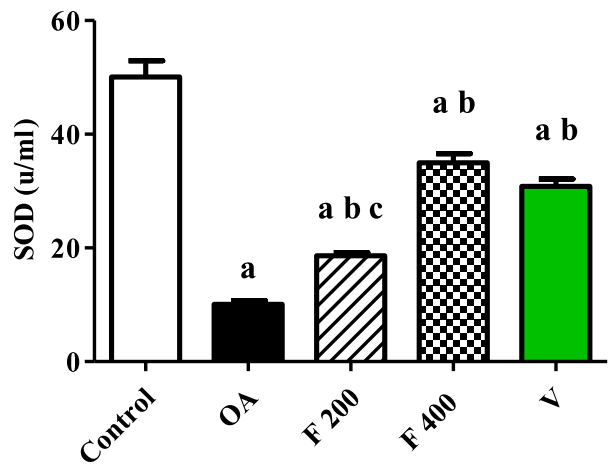

Fig. 5 Serum level of SOD $(\mathrm{U} / \mathrm{ml})$ in the experimental groups. Herbal formula treatment increased serum level of SOD in the osteoarthritic rats at the end of 1 month treatment; $C=$ control; $\mathrm{OA}=$ osteoarthritis; F 200 = herbal formula 200 mg/kg; F 400 = herbal formula $400 \mathrm{mg} / \mathrm{kg} ; \mathrm{V}=$ Voltaren. Results were expressed as mean \pm SEM and analyzed using one-way ANOVA followed by Bonferroni's post hoc test, $a=$ Significant from control at $P<0.0001, b=$ Significant from $O A$ at $P<0.0001, c=$ Significant from $\mathrm{F} 400$ at $P<0.0001$ and negative ion mode tentative identification of major compounds detected is presented in Table 1 .

\section{Histopathological changes associated with glucosamine treatment}

Sections from the control group (C) showed normal histological appearance and proteoglycan content of the cartilage as judged by the preserved integrity of the articular surface, normal orientation and distribution of chondrocytes and the preservation of superficial layer. The OA group showed features of osteoarthritis grade 5 (ORASI grading system) recognized by denudation and erosion of the cartilage with reparative fibrotic changes (clefting, chondrocytes degeneration, calcification, fibrosis and matrix changes).

Other groups showed different grades of OA according to ORASI scale is illustrated in Fig. 6.

\section{Discussion}

Currently the only available pharmacological treatment for OA is non-steroid anti-inflammatory drugs (NSAIDs). Although the use of NSAIDs in osteoarthritis is highly controversial [30], many physicians and patients favor these agents for short and long-term use. However, the therapeutic utility of these agents is frequently limited by the development of side effects especially gastrointestinal ulceration and its complications [31]. Current treatment can control the pain of OA yet side effects could be serious, hence the need to find alternative therapeutic agents. Herbs and extracts present a potential candidate for treatment of OA [5].

In this study we report, for the first time, the beneficial effect of the use of a ginger/curcumin formula in the treatment of OA. Our results show that the ginger/curcumin herbal formula had chondroprotective effect in rat OA model possibly via a combined anti-inflammatory and antioxidant effect.

Our results come in agreement with many researchers who found beneficial effects of ginger and turmeric separately in $\mathrm{OA}$ and other related arthritic diseases. Ginger was effective as indomethacin in relieving symptoms of $\mathrm{OA}$ with negligible side effects [32]. To our knowledge this is the first report that combines ginger and turmeric extract in one formula as a treatment of OA.

Histopathological evaluation of the ginger/curcumin herbal formula treated groups showed different grades of healing according to Osteoarthritis Research Society International (OARSI) grading system (Fig. 6).

To explain the mechanism of action of ginger/curcumin formula, we measured serum level of COMP as well as other inflammatory and oxidative stress markers in our rat model of OA. Our results show that treatment with herbal formula at two different 
Table 1 Chromatographic, mass spectral characteristics and tentative identification of compounds in the herbal formula by UPLC-ESI(-ve)-MS

\begin{tabular}{|c|c|c|c|c|c|}
\hline Compound & $T_{r}(\min )$ & Tentative Identification & Molecular Weight & $\begin{array}{l}(-)-\text { ESI-MS } \\
(\mathrm{m} / \mathrm{z})\end{array}$ & Reference(s) \\
\hline 1 & 2.07 & 10- gingerdiol & 352 & $351[\mathrm{M}-\mathrm{H}]-$ & Tanaka et al. 2015 [28] \\
\hline 2 & 7.76 & Acetoxy-10-gingerol & 392 & $391[\mathrm{M}-\mathrm{H}]-$ & H. Jiang et al. 2005 [25] \\
\hline 3 & 9.43 & 13-Paradol & 376 & $375[\mathrm{M}-\mathrm{H}]-$ & Tanaka et al. 2015 [28] \\
\hline 4 & 14.91 & 1- Dehydro-12- gingerdione & 374 & $373[\mathrm{M}-\mathrm{H}]-$ & H. Jiang et al. 2005 [25] \\
\hline 5 & 16.09 & Methyl-6-gingerol & 308 & $307[\mathrm{M}-\mathrm{H}]-$ & L. B., Ahui M. et al. 2013 [27] \\
\hline 6 & 19.24 & 7- Paradol & 292 & $291[\mathrm{M}-\mathrm{H}]-$ & Tanaka et al. 2015 [28] \\
\hline 7 & 19.86 & Curcumin & 368 & $367[\mathrm{M}-\mathrm{H}]-$ & Herebian et al. 2009 [29] \\
\hline 8 & 22.17 & Methyl diacetoxy-6-gingerdiol & 394 & $393[\mathrm{M}-\mathrm{H}]-$ & Tanaka et al. 2015 [28] \\
\hline 9 & 22.88 & 10-gingerol & 350 & $349[\mathrm{M}-\mathrm{H}]-$ & $\begin{array}{l}\text { H. Jiang et al. } 2005 \text { [25] } \\
\text { TAO et al. } 2009 \text { [26] } \\
\text { L. B., Ahui M. et al. } 2013 \text { [27] }\end{array}$ \\
\hline 10 & 23.6 & 6-Paradol & 278 & $277[\mathrm{M}-\mathrm{H}]-$ & $\begin{array}{l}\text { TAO et al. } 2009 \text { [26] } \\
\text { Tanaka et al. } 2015 \text { [25] }\end{array}$ \\
\hline 11 & 26.29 & Dihydrocurumin & 370 & $369[\mathrm{M}-\mathrm{H}]-$ & Herebian et al. 2009 [29] \\
\hline
\end{tabular}
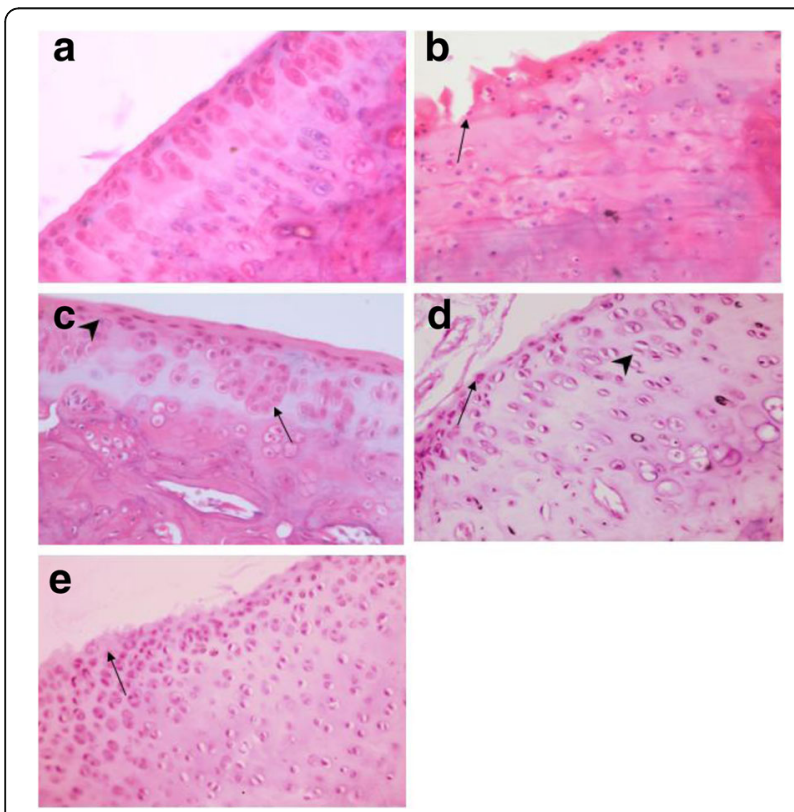

Fig. 6 Photomicrograph of a control group showing normal chondrocytes shape and orientation. b From osteoarthritis group showing denudation, erosion, clefting (arrow) and degeneration of chondrocytes. c F400 group showing superficial fibrillation (arrow head) with more or less normal orientation and some edema (arrow). d From F200 group superficial fibrillation (arrow), proliferation and clustering of chondrocytes, (arrow head) cracking and simple fissures. e From Voltarin treated group showing Loss of superficial layer, chondrocytes necrosis and simple fissures (arrow) H\&Ex400 doses significantly reduced the serum level of COMP compared to OA group ( $P$ value $<0.0001)$. The herbal formula at dose $400 \mathrm{mg} / \mathrm{kg}$ had similar effects on serum COMP levels as Voltaren ${ }^{\circ}$ as there was a nonsignificant difference was found between F 400 and V groups (Fig. 1). These results on serum COMP could in part explain the effect of herbal formula observed in our study.

COMP is a large extracellular matrix protein, and a structural component of cartilage. Elevated levels of COMP are released during erosive joint disease such as rheumatoid arthritis and osteoarthritis [33]. The concentration of COMP in OA group was found to be increased over reference levels in the early stages of knee OA development. This is due to series of catabolic events undergoing in articular cartilage, which results in high turnover rate by the chondrocytes in order to repair the cartilage matrix. This process led first to dismantling of cartilage matrix and then a net loss of tissue [34]. There was a significant difference in the concentration of COMP biomarkers between patients with shorter and longer osteophytes on Kondyles of tibia and femur [14]. In another study patients with longer medial osteophytes and with great capsular distension had higher levels of HA and COMP in serum compared to patients with shorter osteophytes [35]. This suggests a role for COMP in the pathogenesis of OA [14].

HA is considered to be a good marker of synovitis in $\mathrm{OA}$ as it reflects local inflammation in synovial lining and, cartilage degradation [33]. Our results show that treatment with herbal formula at two-dose levels, significantly reduced serum level of HA compared to OA group ( $P$ value $<0.0001)$; while its level was significantly increased in OA group compared to control group (Fig. 1). 
MPO is released by activated neutrophils and used as a marker of leukocyte recruitment and function and subsequent inflammation. MPO concentration is related to inflammatory activity and could play an important role in the maintenance of oxidative stress in OA [36]. In this study MPO was significantly increased in OA group compared to control group (Fig. 2). On the other hand it was reduced after 1-month treatment with the herbal formula at two-dose levels ( $P$ value $<0.0001)$.

Increased inflammation is the consequence of many factors, including mechanical overloading, joint injury, adipose tissue, and cartilage matrix fragments. IL- $1 \beta$ is considered one of the most prominent pro-inflammatory cytokines involved in OA. Elevated level of IL-1 $\beta$ is found in OA joint tissues, including the articular cartilage, subchondral bone, synovial fluid and synovium. IL-1 $\beta$ alters the homeostatic balance of chondrocytes by suppressing anabolic activity, stimulating catabolic breakdown of the articular cartilage, and increasing production of inflammatory mediators and reactive oxygen species (ROS) [37].

Ramadan et al., [21] found that the dried rhizomes of turmeric and ginger, separately, reduced inflammation by inhibiting the nuclear factor- $\mathrm{kB}$ activation. This lead to inhibition of gene expression of proinflammatory cytokines (TNF- $\alpha$ and IL-1 $\beta$ ) in adjuvant-induced rat arthritis. This theory may explain why herbal formula was more effective in reducing inflammation and oxidative stress levels due to the synergistic effects of ginger and turmeric in herbal formula extract (Fig. 7).

Lipid peroxidation may lead to production of several toxic products as MDA. MDA showed a significant decrease in groups treated with herbal formula at two dose levels compared to OA group $(P$ value $<0.0001)$.
This result comes in agreement with a study that found that there was significant decrease in lipid peroxidation groups treated with Zingiber officinale (ginger) when compared to animals treated with DMBA alone. The observed reduction in the level of lipid peroxidation in herbal formula treated animals was presumably due to the ability of ginger to scavenge the hydroxyl and peroxyl radicals $[38,39]$.

To evaluate the antioxidant effect of the formula we measured serum SOD activity. SOD showed significant elevation in herbal formula treated groups at two dose levels compared to OA group $(P$ value $<0.0001$ ). This could indicate a direct or indirect (enhancing hepatic antioxidant activity) radical scavenging capability of the formula. Aqueous and ethanolic extract of Zingiber officinale was shown to have hepato-protective effect against acetaminophen-induced acute toxicity due to its antioxidant activity $[39,40]$.

\section{Conclusion}

The composition and characterization of the herbal formula hydro-ethanolic extract confirmed the identification of 11 curcumin and gingerol derivatives. The ginger/curcumin 1:1 herbal formula had chondroprotective effect in rat OA model in rats. Herbal formula treatment also reduced oxidative stress levels. Herbal formula at concentration of $400 \mathrm{mg} / \mathrm{kg}$ had more potent anti-inflammatory and anti oxidant effect compared with concentration of $200 \mathrm{mg} / \mathrm{kg}$. Further pharmacological and clinical studies are still needed to evaluate this effect as well as its potential use in treatment of $\mathrm{OA}$ in human.

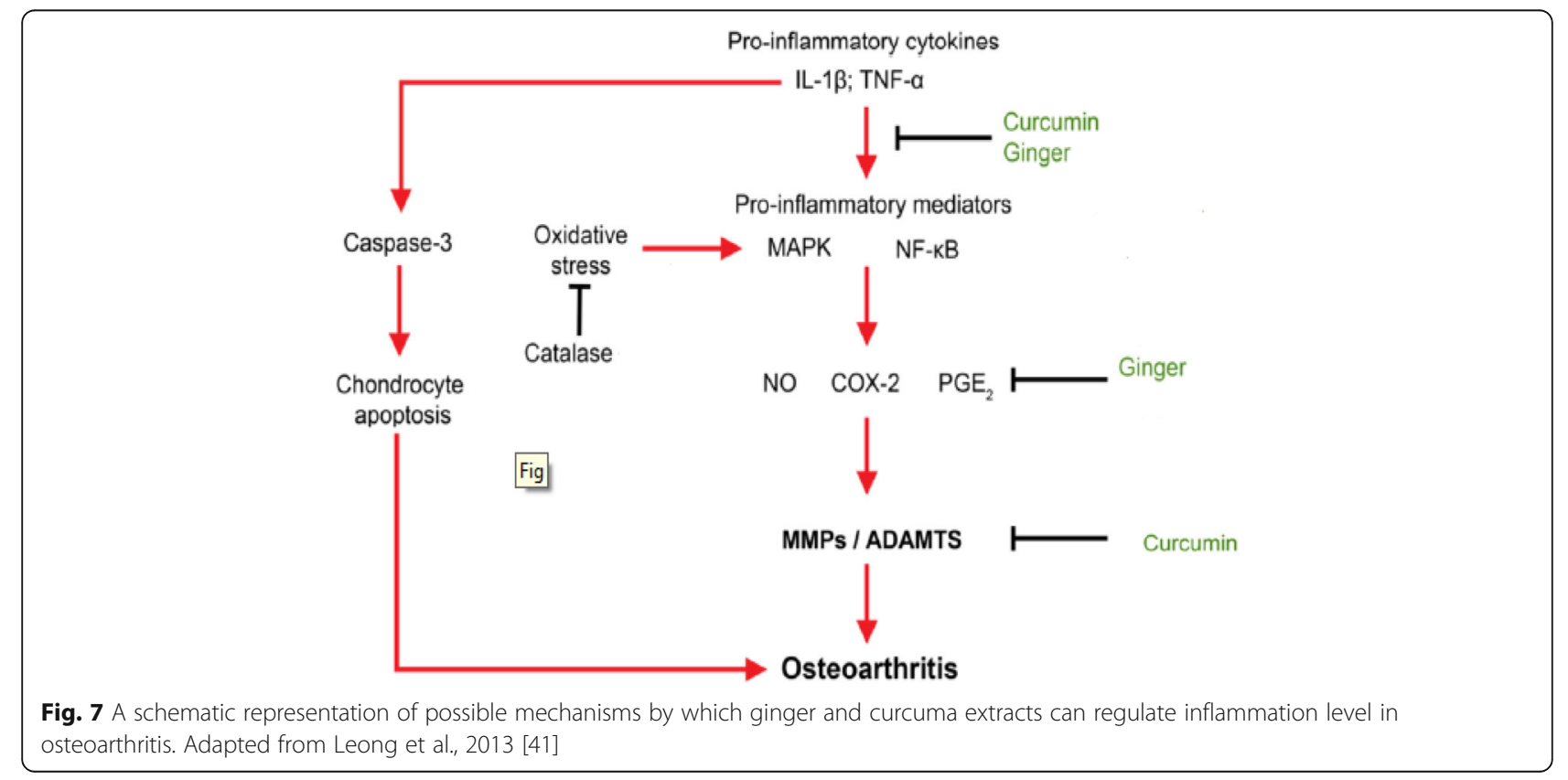




\section{Abbreviations}

COMP: Cartilage oligomeric matrix protein; HA: Hyaluronic acid; IL1ß: Interleukin-1 beta; MDA: Malondialdehyde; MIA: Monosodium lodoacetate; MPO: Myeloperoxidase; OA: Osteoarthritis; OARSI: Osteoarthritis Research Society International; ROS: Reactive oxygen species; SOD: Superoxide dismutase

\section{Acknowledgements}

The authors would like to acknowledge Dr. Nashwa Waly, Professor of Small Animal Medicine Assiut University, Egypt, for her invaluable editorial assistance.

\section{Funding}

This research is not supported by any funding agency.

\section{Availability of data and materials}

The datasets supporting the conclusions of this article are included within the article and its additional files. Any further data will be available upon request.

\section{Authors' contributions}

NMA and NEW contributed equally to the experimental design, execution of the experiments, data, sample collection the study, conduction of biochemical analyses, interpretation of data and drafting the manuscript. NMA performed the statistical analyses of this study. MHE performed phytochemical analyses. AR executed the histopatholgical examination and scoring. All authors read and approved the final manuscript.

\section{Ethics approval}

Animal care and handling was performed in conformance with approved protocols of Cairo University and Egyptian Community guidelines for animal care. Research Ethics Committee at MSA School of Pharmacy approved the protocol of this study.

\section{Consent for publication}

Not applicable.

\section{Competing interests}

The authors declare that they have no competing interest.

\section{Publisher's Note}

Springer Nature remains neutral with regard to jurisdictional claims in published maps and institutional affiliations.

\section{Author details}

'Department of Biochemistry, Faculty of Pharmacy, MSA University, Giza 11787, Egypt. ${ }^{2}$ Department of Pharmacognosy, Faculty of Pharmacy, MSA University, Giza 11787, Egypt. ${ }^{3}$ Department of Pathology Faculty of Medicine, Assiut University, Assiut 71515, Egypt. ${ }^{4}$ Department of Physiology, Faculty of Medicine, Helwan University, Cairo, 11795, Egypt.

\section{Received: 29 May 2017 Accepted: 14 November 2017}

\section{Published online: 22 November 2017}

\section{References}

1. Zhang $W$, Ouyang $H$, Dass $C R$, Xu J. Current research on pharmacologic and regenerative therapies for osteoarthritis. Bone Res. 2016:4:15040.

2. Hootman JM, Helmick CG. Projections of US prevalence of arthritis and associated activity limitations. Arthritis Rheum. 2006:54(1):226-9.

3. Cialdai C, Giuliani S, Valenti C, Tramontana M, Maggi CA. Comparison between oral and intra-articular antinociceptive effect of dexketoprofen and tramadol combination in monosodium iodoacetate-induced osteoarthritis in rats. Eur J Pharmacol. 2013;714(1-3):346-51

4. Hunter DJ, Felson DT. Osteoarthritis. BMJ. 2006;332(7542):639-42.

5. Al-Saffar FJ, Ganabadi S, Fakurazi S, Yaakub H, Lip M. Chondroprotective effect of Zerumbone on monosodium lodoacetate induced osteoarthritis in rats. J Appl Sci. 2010;10(4):248-60.

6. Berenbaum F. Osteoarthritis year 2010 in review: pharmacological therapies. Osteoarthr Cartil. 2011;19(4):361-5.

7. Hawker GA, Mian S, Bednis K, Stanaitis I. Osteoarthritis year 2010 in review: non-pharmacologic therapy. Osteoarthr Cartil. 2011;19(4):366-74.
8. Nagase H, Kumakura S, Shimada K. Establishment of a novel objective and quantitative method to assess pain-related behavior in monosodium iodoacetate-induced osteoarthritis in rat knee. J Pharmacol Toxicol Methods. 2012;65(1):29-36.

9. Bianchi E, Di Cesare Mannelli L, Menicacci C, Lorenzoni P, Agliano M, Ghelardini C. Prophylactic role of acetyl--carnitine on knee lesions and associated pain in a rat model of osteoarthritis. Life Sci. 2014;106(1-2):32-9.

10. Moilanen $L$, Hamalainen $M$, Nummenmaa $E$, Ilmarinen $P$, Vuolteenaho $K$, Nieminen RM, Lehtimaki L, Moilanen E. Monosodium iodoacetate-induced inflammation and joint pain are reduced in TRPA1 deficient mice-potential role of TRPA1 in osteoarthritis. Osteoarthr Cartil. 2015;23(11):2017-26.

11. Aborehab NM, El Bishbishy MH, Waly NE. Resistin mediates tomato and broccoli extract effects on glucose homeostasis in high fat diet-induced obesity in rats. BMC Complement Altern Med. 2016;16:225

12. Ghavipour M, Sotoudeh G, Ghorbani M. Tomato juice consumption improves blood antioxidative biomarkers in overweight and obese females. Clin Nutr. 2015:34(5):805-9.

13. Ghavipour M, Saedisomeolia A, Djalali M, Sotoudeh G, Eshraghyan MR, Moghadam AM, Wood LG. Tomato juice consumption reduces systemic inflammation in overweight and obese females. Br J Nutr. 2013;109(11):2031-5.

14. Zivanovic S, Rackov LP, Zivanovic A, Jevtic M, Nikolic S, Kocic S. Cartilage oligomeric matrix protein - inflammation biomarker in knee osteoarthritis. Bosn J Basic Med Sci. 2011;11(1):27-32.

15 Ojewole JA. Analgesic, antiinflammatory and hypoglycaemic effects of ethanol extract of Zingiber Officinale (roscoe) rhizomes (Zingiberaceae) in mice and rats. Phytother Res. 2006;20(9):764-72.

16 al-Yahya MA, Rafatullah S, Mossa JS, Ageel AM, Parmar NS, Tariq M. Gastroprotective activity of ginger zingiber officinale rosc., in albino rats. Am J Chin Med. 1989;17(1-2):51-6.

17 Anosike CA, Obidoa O, Ezeanyika LUS, Nwuba MM. Anti-inflammatory and anti-ulcerogenic activity of the ethanol extract of ginger (Zingiber Officinale). Afr J Biochem Res, 2009:3(12):379-84.

18 Chin KY. The spice for joint inflammation: anti-inflammatory role of curcumin in treating osteoarthritis. Drug Des Devel Ther. 2016;10:3029-42.

19 Rahimnia AR, Panahi Y, Alishiri G, Sharafi M, Sahebkar A. Impact of supplementation with Curcuminoids on systemic inflammation in patients with knee osteoarthritis: findings from a randomized double-blind placebocontrolled trial. Drug Res (Stuttg). 2015:65(10):521-5.

20 Panahi Y, Alishiri GH, Parvin S, Sahebkar A. Mitigation of systemic oxidative stress by Curcuminoids in osteoarthritis: results of a randomized controlled trial. J Diet Suppl. 2016;13(2):209-20.

21 Ramadan G, Al-Kahtani MA, El-Sayed WM. Anti-inflammatory and anti-oxidant properties of Curcuma Longa (turmeric) versus Zingiber Officinale (ginger) rhizomes in rat adjuvant-induced arthritis. Inflammation. 2011;34(4):291-301.

22 Shankar TN, Shantha NV, Ramesh HP, Murthy IA, Murthy VS. Toxicity studies on turmeric (Curcuma Longa): acute toxicity studies in rats, guineapigs \& monkeys. Indian J Exp Biol. 1980;18(1):73-5.

23 Vogler GA, Suckow MA, Weisbroth S, Franklin CL. Anesthesia and analgesia in the laboratory rat. New York: Elsevier Academic Press; 2006. p. 627-95.

24 Pritzker KP, Gay S, Jimenez SA, Ostergaard K, Pelletier JP, Revell PA, Salter D, van den Berg WB. Osteoarthritis cartilage histopathology: grading and staging. Osteoarthr Cartil. 2006;14(1):13-29.

25 Jiang H, Solyom AM, Timmermann BN, Gang DR. Characterization of gingerol-related compounds in ginger rhizome (Zingiber Officinale Rosc.) by high-performance liquid chromatography/electrospray ionization mass spectrometry. Rapid Commun Mass Spectrom. 2005;19(20):2957-64.

26 Tao Y, Li W, Liang W, Van Breemen RB. Identification and quantification of gingerols and related compounds in ginger dietary supplements using high-performance liquid chromatography-tandem mass spectrometry. J Agric Food Chem. 2009;57(21):10014-21.

27 Ahui MLB, Konan AB, Zannou-Tchoko VJ, Amonkan AK, Kati-Coulibaly S, Offoumou MA. Identification of Gingerols in ginger (Zingiber Officinale roscoe) by high performance liquid chromatography-tandem mass spectrometry and pharmacologic studies of its aqueous extract on the rabbit isolated duodenum contractility. J Phys Pharm Adv. 2013;3(2):16-26.

28 Tanaka K, Arita M, Sakurai H, Ono N, Tezuka Y. Analysis of chemical properties of edible and medicinal ginger by metabolomics approach. Biomed Res Int 2015:2015:671058.

29 Herebian D, Choi JH, Abd El-Aty AM, Shim JH, Spiteller M. Metabolite analysis in Curcuma Domestica using various GC-MS and LC-MS separation and detection techniques. Biomed Chromatogr. 2009;23(9):951-65. 
30 Nelson AE, Allen KD, Golightly YM, Goode AP, Jordan JM. A systematic review of recommendations and guidelines for the management of osteoarthritis: the chronic osteoarthritis management initiative of the U.S. bone and joint initiative. Semin Arthritis Rheum. 2014;43(6):701-12.

31 Bove SE, Calcaterra SL, Brooker RM, Huber CM, Guzman RE, Juneau PL, Schrier DJ, Kilgore KS. Weight bearing as a measure of disease progression and efficacy of anti-inflammatory compounds in a model of monosodium iodoacetate-induced osteoarthritis. Osteoarthr Cartil. 2003;11(11):821-30.

32 Haghighi ATN, Owlia MB. Effects of ginger on primary knee osteoarthritis. Indian J Rheumatol. 2006;1:3-7.

33 Ramonda R, Lorenzin M, Modesti V, Campana C, Ortolan A, Frallonardo P, Punzi L. Serological markers of erosive hand osteoarthritis. Eur J Intern Med. 2013;24(1):11-5.

34 Verma P, Dalal K. Serum cartilage oligomeric matrix protein (COMP) in knee osteoarthritis: a novel diagnostic and prognostic biomarker. J Orthop Res. 2013;31(7):999-1006

35 Jung YO, Do JH, Kang HJ, Yoo SA, Yoon CH, Kim HA, Cho CS, Kim WU. Correlation of sonographic severity with biochemical markers of synovium and cartilage in knee osteoarthritis patients. Clin Exp Rheumatol. 2006:24(3):253-9.

36 Punzi L, Ramonda R, Deberg M, Frallonardo P, Campana C, Musacchio E, Henrotin Y. Coll2-1, Coll2-1NO2 and myeloperoxidase serum levels in erosive and non-erosive osteoarthritis of the hands. Osteoarthr Cartil. 2012;20(6):557-61.

37 Kapoor M, Martel-Pelletier J, Lajeunesse D, Pelletier JP, Fahmi H. Role of proinflammatory cytokines in the pathophysiology of osteoarthritis. Nat Rev Rheumatol. 2011;7(1):33-42.

38 Blessy D, Suresh K, Manoharan S, Arokia A, Vijayaan MA and, Sugunadevi G. Evaluation of chemo preventive potential of Zingiber Officinale roscoe ethanolic root extract on 7, 12-dimethyl Benz[a] anthracene induced oral carcinogenesis. Res J Agric Biol Sci. 2009;5(5): 775 - 81.

39 Al-Kushi AG, El-Boshy ME, ElSawy NA, Shaikh Omar OA, Header EA. Pathological comparative studies on aqueous and Ethanolic extracts of Zingiber Officinale on antioxidants and Hypolipidemic effects in rats. Life Science Journal. 2013;10(2):2393-403.

40 Ajith TA, Hema U, Aswathy MS. Zingiber Officinale roscoe prevents acetaminophen-induced acute hepatotoxicity by enhancing hepatic antioxidant status. Food Chem Toxicol. 2007;45(11):2267-72

41 Leong DJ, Choudhury M, Hirsh DM, Hardin JA, Cobelli NJ, Sun HB. Nutraceuticals: potential for chondroprotection and molecular targeting of osteoarthritis. Int J Mol Sci. 2013;14(11):23063-85.

\section{Submit your next manuscript to BioMed Central and we will help you at every step:}

- We accept pre-submission inquiries

- Our selector tool helps you to find the most relevant journal

- We provide round the clock customer support

- Convenient online submission

- Thorough peer review

- Inclusion in PubMed and all major indexing services

- Maximum visibility for your research

Submit your manuscript at www.biomedcentral.com/submit 